\title{
Communication Vagueness in the Literature Review Section of Journal Article Submissions
}

\author{
Anthony J. Onwuegbuzie (Corresponding author) \\ Department of Educational Leadership and Counseling, Sam Houston State University \\ Box 2119, Huntsville, Texas 77341-2119, USA \\ $\&$ \\ Distinguished Visiting Professor, Faculty of Education, University of Johannesburg \\ B-Ring 433, Kingsway Campus, Auckland Park, South Africa \\ E-mail: tonyonwuegbuzie@aol.com
}

Received: April 10, 2018 Accepted: June 5, 2018 Published: June 9, 2018

doi:10.5296/jei.v4i1.12995 URL: https://doi.org/10.5296/jei.v4i1.12995

\begin{abstract}
Evidence has been provided about the importance of avoiding American Psychological Association (APA) errors in the abstract, body, reference list, and table sections of empirical research articles. Specifically, authors are significantly more likely to have their manuscripts rejected for publication if they fail to avoid APA violations - and, thus, do not write with discipline - in these sections. In addition to adhering to APA, writing with discipline also includes avoiding communication vagueness. Thus, I analyzed communication vagueness in the literature review section of 71 manuscripts submitted to the journal Research in the Schools over a 3-year period. Findings revealed that the frequency of communication vagueness differed in relation to the following: (a) number of APA errors, (b) gender of lead author, (c) genre of manuscript, and (d) adjudication decisions. In particular, certain communication vagueness categories were statistically significant and practically significant predictors of whether or not a manuscript is rejected for publication by the editor. Implications of these findings are discussed.
\end{abstract}

Keywords: Communication vagueness, Research in the Schools, Writing with discipline, Manuscript rejection, Manuscript acceptance

\section{Introduction}

As identified by Onwuegbuzie and Frels (2016), there are 12 broad components of the empirical research process (i.e., quantitative research studies, qualitative research studies, and 


\section{Macrothink

mixed methods research studies), namely: problem statement, literature review, theoretical/conceptual framework, research question(s), hypotheses, participants, instruments, procedures, analyses, interpretation of the findings, directions for future research, and implications for the field. Of these components, the literature review component represents the most important step of the research process in all empirical studies because it is the most effective way of becoming familiar with previous assumptions, ideas, beliefs, propositions, theories, schemas, models, hypotheses, findings, interpretations, research methodologies, and the like presented by researchers pertaining to a given topic of interest, thereby providing a foundation for meaningful research (Boote \& Beile, 2005; Onwuegbuzie, Collins, Leech, Dellinger, \& Jiao, 2010; Onwuegbuzie \& Frels, 2012). As declared by Boote and Beile (2005), "A substantive, thorough, sophisticated literature review is a precondition for doing substantive, thorough, sophisticated research" (p. 3). More specifically, Onwuegbuzie and Frels (2016) identified reasons for conducting a review of the literature. Figure 1 presents Onwuegbuzie and Frels's (2016) typology of reasons for a literature review that comprises some of the most common reasons that researchers use to conduct the literature review. These reasons have been categorized into three major areas: topic-driven focused, method-driven focused, and connection-driven focused. 


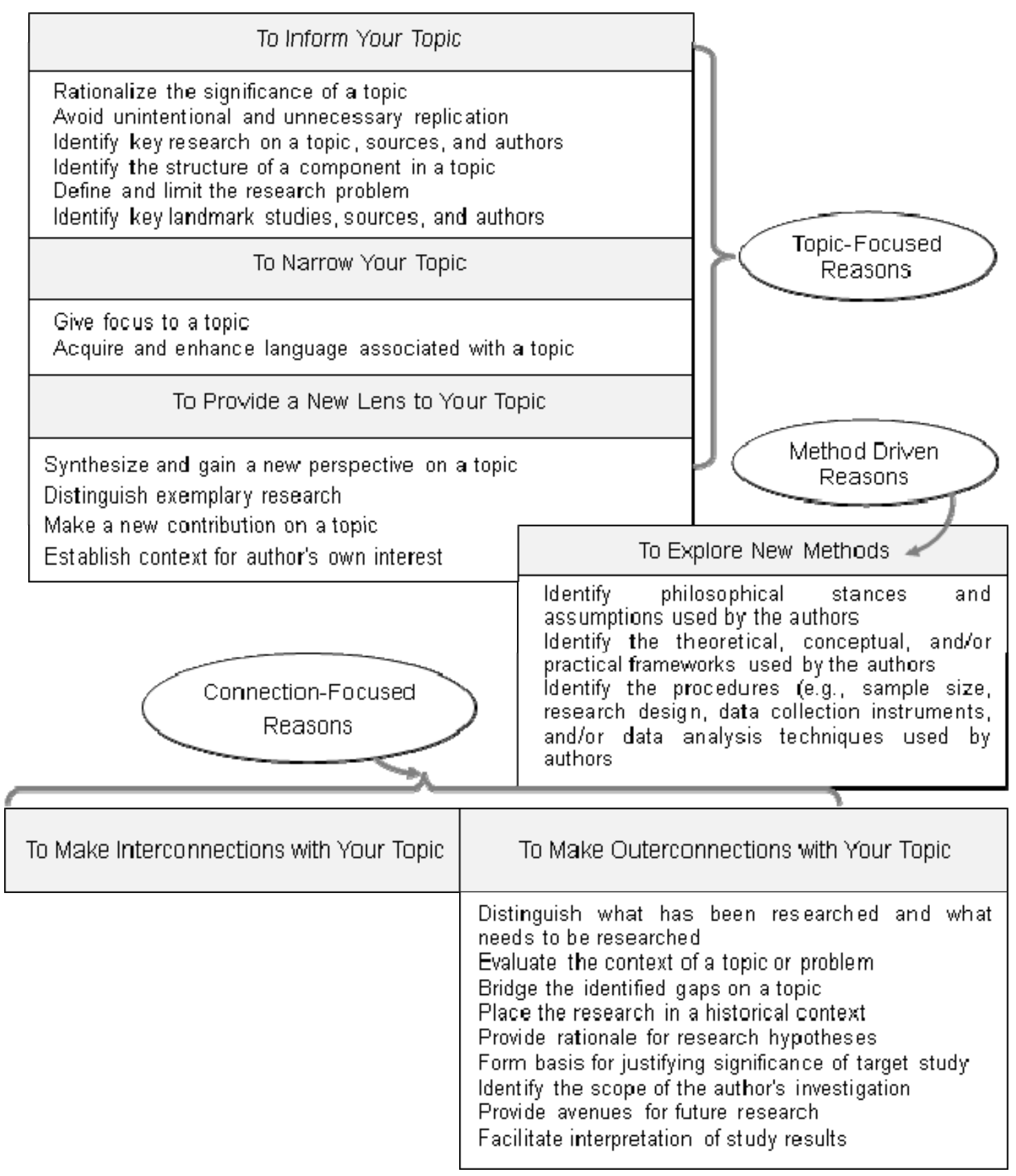

Figure 1. Common reasons for conducting a literature review (Onwuegbuzie \& Frels, 2016)

Note. Adapted from "Seven steps to a comprehensive literature review: A multimodal and cultural approach," by Onwuegbuzie and Frels (2016, p. 15). Copyright 2016 by Sage Publications.

Despite its importance, there are fewer published works devoted exclusively or even primarily to the literature review component than any other component of the empirical research process (Onwuegbuzie et al., 2010). Consistent with this assertion, Onwuegbuzie and Leech (2005) documented that even though the vast majority of research methodology 
textbook authors devote at most one chapter to discussing the literature review process, they devote multiple chapters in these same textbooks to other phases of the research process, such as the research design phase and data analysis phase (Boote \& Beile, 2005; Onwuegbuzie \& Leech, 2005). As such, it could be inferred that although these textbook authors recognize the importance of the literature review process, they place much greater weight on other components of the research process - particularly, the research design, data collection, and data analysis components. Similarly, more than three decades ago, Zaporozhetz (1987) documented that faculty members ranked the literature review chapter as being the least important chapter in a standard dissertation and that most dissertation chairs/supervisors and students viewed the literature review process as representing the most straightforward chapter that doctoral candidates should be able to complete by themselves with minimal assistance from their chairs/supervisors. Unfortunately, today, these findings still appear to apply (Combs, Bustamante, \& Onwuegbuzie, 2010; Onwuegbuzie \& Frels, 2016).

In addition, relatively few doctoral students receive formal training on how to conduct a literature review or even how to write-up the literature review. And even fewer doctoral students have the opportunity to take a formal literature review course. As an example, Onwuegbuzie, Leech, and Collins (2011), who examined the website of every National Association of School Psychologists (NASP)-approved graduate-level school psychology program $(n=175)$ in the United States, documented that only four programs $(2.3 \%)$ offered a literature review course as either a required course or as an elective. Onwuegbuzie et al.'s (2011) finding supported Cooper's (1985) contention that, "Students in education ... can take five or six statistics or methods courses without ever directly addressing the problems and procedures of literature review" (p. 33). Thus, the hidden curriculum in doctoral programs around the world is that, compared to research methodology courses (e.g., statistics courses, qualitative research courses, measurement courses), the literature review is of secondary importance (Boote \& Beile, 2005; Onwuegbuzie \& Frels, 2016).

Thus, with such lack of guidance about how to write literature reviews, it should not be surprising that many early career researchers and students (cf. Boote \& Beile, 2005) and experienced researchers (Alton-Lee, 1998; LeCompte, Klingner, Campbell, \& Menk, 2003; Onwuegbuzie \& Daniel, 2005) alike experience difficulties writing quality literature reviews. In fact, Onwuegbuzie and Daniel (2005), who examined 52 manuscripts submitted to a nationally refereed research journal, Research in the Schools (RITS), over a 2-year period, reported that $40 \%$ of the submitted manuscripts contained inadequate literature reviews, and that the authors of these manuscripts were more than six times more likely than were their counterparts to have their manuscripts rejected for publication. Several years earlier, Alton-Lee (1998), who examined reviewers' comments for 58 manuscripts submitted to the Teaching and Teacher Education journal over a 1-year period (i.e., 142 reviews that yielded 369 distinct criticisms), reported that the criticisms associated with the literature review of these manuscripts were inadequate literature reviews $(50.0 \%)$, theoretical flaws $(53.4 \%)$, parochial focus $(39.7 \%)$, failure to link findings to the extant literature $(34.4 \%)$, and failure to contribute to international literature (36.2\%). At the doctoral level, Boote and Beile (2005) contended that "Despite the assumption that dissertation literature reviews are comprehensive 
and up-to-date, the dirty secret known by those who sit on dissertation committees is that most literature reviews are poorly conceptualized and written" (p. 4). Furthermore, a link has been identified between the quality of a literature review in a doctoral dissertation and both the quality of the ensuing methodology and the doctoral candidates' ability to conduct substantive, defensible research (Mullins \& Kiley, 2002).

In an attempt to develop a framework from which to analyze literature reviews in doctoral dissertations in the field of education, Boote and Beile (2005) arrived at a 12-item scoring rubric that were grouped into five categories, as follows: (a) Coverage, which assesses how well the literature reviewer justified criteria for inclusion and exclusion from review; (b) Synthesis, which assesses how well the literature reviewer summarized, analyzed, and synthesized the selected literature on a topic; (c) Methodology, which assesses how well the literature reviewer "identified the main methodologies and research techniques that have been used in the field, and analyzed their advantages and disadvantages" (p. 7); (d) Significance, which assesses how well the literature reviewer rationalized both the practical and scholarly significance of the research problem; and (e) Rhetoric, which assesses how well the literature review "was written with a coherent, clear structure that supported the review" (p. 9). Interestingly, it could be argued that because each of these categories assess how well a literature reviewer coveys meaning of some aspect of the literature review, as a set, they represent an assessment of clarity.

Unfortunately, a potential flaw associated with literature reviews is clarity. Indeed, Onwuegbuzie and Poth (2015), who examined factors that determined reviewers' appraisal of mixed methods research manuscripts submitted to a special issue of the International Journal of Qualitative Methods for review for possible publication, documented that clarity is an important determinant of the quality and effectiveness of authors' writing that was cited by the reviewers. Related to clarity is communication vagueness. In fact, in the field of research in general and the field of social and behavioral sciences research in particular, it is necessary for literature reviewers to communicate with diverse audiences (e.g., researchers, practitioners, stakeholders). Moreover, researchers should not write their literature reviews under the assumption that the consumers of their literature reviews have a shared knowledge or understanding of the underlying topic, or of relevant research methodologies associated with the topic. And, as noted by Boote and Gaudelli (2002), there is often not a common agreement of what constitutes an important research problem to investigate for a given topic. As such, it is essential for researchers to maximize communication in their literature review narratives. Indeed, it might be expected that communication vagueness-particularly, the vagueness of words written (cf. Hiller, 1971) — to some degree, represents a feature of poorly written literature reviews. However, to date, this link has not been investigated.

\subsection{Theoretical Framework}

Hiller, Fisher, and Kaess (1969), who conceptualized communication vagueness, defined communication vagueness as a "psychological construct, which refers to the state of mind of a performer who does not sufficiently command the facts or the understanding required for maximally effective communication" (p. 670). Accordingly, they identified the following 10 
categories of communication vagueness:

(1) ambiguous designation (i.e., something potentially specifiable is mentioned but not definitely identified; e.g., stuff, and so on);

(2) negated intensifiers (i.e., negations can be evasions; e.g., not quite; not necessarily);

(3) approximation (i.e., use reflects real or referential vagueness or imprecise knowledge; e.g., sort of, pretty much);

(4) bluffing and recovery (i.e., when a speaker/writer is not communicating effectively and attempts to shift responsibility for making sense of content to the listener/reader; e.g., actually, anyway);

(5) admission of error (i.e., repeated admissions of error indicate lack of confidence or lack of competence; e.g., I made a mistake, I don't know);

(6) indefinite amount (i.e., an amount that is potentially knowable but is not specified; e.g., some, a couple, a little, a lot);

(7) multiplicity (i.e., pseudospecification or glossing over of complexity; e.g., types, kinds);

(8) probability and possibility (i.e., indicates lack of clarity or lack of definite knowledge; e.g., at times, generally);

(9) reservations (i.e., expressions of doubt or reluctance to commit to a specific point of view; i.e., appear, seems); and

(10) anaphora (i.e., excessive and repetitious use of pronouns instead of direct references makes content more difficult to follow; e.g., she, he, it, them, latter, former).

\subsection{Purpose of Study}

With the aforementioned discussion in mind, the purpose of my study was to examine the prevalence of communication vagueness in the literature review section of manuscripts submitted to a journal for consideration for publication. A second purpose was to examine the importance of communication vagueness in the literature review section on the quality of empirical manuscripts submitted to a journal for consideration for publication, as indicated by their eventual disposition (i.e., accept/revise and resubmit vs. reject). Specifically, the thoroughness of the inquiry led to the following five research questions being addressed:

(1) What is the prevalence of communication vagueness among manuscripts submitted to a journal?

(2) What is the relationship between the frequency of communication vagueness and style guide errors (i.e., APA errors) among manuscripts submitted to a journal?

(3) What is the relationship between the frequency of communication vagueness and citation errors among manuscripts submitted to a journal?

(4) What is the relationship between the frequency of communication vagueness and select 
demographic characteristics (i.e., number of authors, gender of the lead author, genre of manuscript) among manuscripts submitted to a journal?

(5) What is the relationship between the frequency of communication vagueness and manuscript disposition among manuscripts submitted to a journal?

\section{Method}

\subsection{Sample Size and Procedures}

To analyze the prevalence and predictability of communication vagueness among manuscripts submitted to a journal, I examined 71 manuscripts submitted to RITS over a 3-year period (i.e., 2014-2015). These manuscripts represented approximately 50\% of all manuscripts submitted to this journal over this time frame, which made these findings generalizable at the very least to the population of manuscripts submitted to RITS. The sample size of 71 was selected via an a priori statistical power analysis. Specifically, it represented the sample size needed to detect a moderate multivariate relationship (i.e., discriminant analysis; $f=.27$ ) simultaneously for the dependent measures (i.e., 10 communication vagueness categories) between the two groups (i.e., manuscripts that were rejected vs. manuscripts that were not rejected) at the $5 \%$ level of statistical significance and a power of .80 .

For each of the 71 manuscripts submitted to RITS over this time period, I meticulously documented every grammatical error, APA error, and citation error committed by these 71 sets of authors. Each manuscript took up to 4 hours to identify all the grammatical errors, APA errors, and citation errors - representing as much as 284 hours of coding. In addition, I noted several demographic features of the manuscript (e.g., number of authors, gender of lead author, genre of manuscript), as well as the disposition of the manuscript.

Next, I used QDA Miner, Version 4.1.33 (Provalis Research, 2014a), to conduct an initial coding of the 71 manuscripts for the communication vagueness contained in them, as well as to code characteristics of each manuscript (e.g., genre of manuscript [i.e., qualitative vs. quantitative vs. mixed methods vs. non-empirical]; number of authors, page length, word count). Then, I used WordStat 7.1.6 (Provalis, 2014b) to conduct a quantitative content analysis of the communication vagueness in the literature review section of each manuscript with respect to the aforementioned 10 categories of communication vagueness. Finally, I used SPSS to conduct a discriminant analysis to determine the predictability of select communication vagueness categories with respect to manuscript disposition (i.e., reject vs. non-reject [i.e., accept, revise and resubmit]) among manuscripts submitted to RITS. As such, the data set created was extremely rich.

\subsection{Analysis}

Descriptive statistics (i.e., measures of central tendency) were used to address the first research question (i.e., What is the prevalence of communication vagueness among manuscripts submitted to a journal?). Furthermore, a multiple regression analysis was conducted to determine which communication vagueness categories, if any, predicted the 
number of APA errors committed (Research Question 2), the number of citation errors committed (Research Question 3), and demographic characteristics (e.g., number of authors) (Research Question 4). Finally, a discriminant analysis was used to determine which communication vagueness categories, if any, discriminated the gender of the lead author and genre of manuscript (Research Question 4) and the two sets of manuscripts (i.e., manuscripts that were rejected vs. manuscripts that were not rejected) (Research Question 5).

\section{Results}

3.1 Research Question 1. What Is the Prevalence of Communication Vagueness Among Manuscripts Submitted to a Journal?

Table 1 presents the frequencies of the 10 communication vagueness categories. It can be seen from this table that anaphora was the most common category, followed by multiplicity, and then probability and possibility. These categories were, by far, the most common.

Table 1. Frequencies of communication vagueness categories

\begin{tabular}{|l|l|l|l|l|l|l|}
\hline Category & $M$ & $S D$ & Minimum & Maximum & $\begin{array}{l}\text { Mean number } \\
\text { per word }\end{array}$ & $\begin{array}{l}S D \text { of number } \\
\text { per word }\end{array}$ \\
\hline Ambiguous designation & 3.93 & 5.70 & 0 & 33 & .0008 & .0013 \\
\hline Negated intensifiers & 0.69 & 1.40 & 0 & 10 & .0001 & .0002 \\
\hline Approximation & 2.07 & 3.10 & 0 & 18 & .0004 & .0005 \\
\hline Bluffing and recovery & 1.27 & 2.14 & 0 & 14 & .0003 & .0004 \\
\hline Admission of error & 0.01 & 0.12 & 0 & 1 & .000002 & .00002 \\
\hline Indefinite amount & 4.21 & 5.35 & 0 & 32 & .0008 & .0009 \\
\hline Multiplicity & 14.59 & 12.31 & 1 & 63 & .0028 & .0023 \\
\hline Probability and possibility & 9.61 & 15.63 & 0 & 123 & .0017 & .0023 \\
\hline Reservations & 2.35 & 3.20 & 0 & 14 & .0004 & .0006 \\
\hline Anaphora & 36.72 & 34.96 & 5 & 205 & .0067 & .0058 \\
\hline Total & 75.27 & 74.99 & 12 & 494 & .0139 & .0122 \\
\hline
\end{tabular}

\subsection{Research Question 2. What Is the Relationship Between the Frequency of Communication} Vagueness and Style Guide Errors (i.e., APA Errors) Among Manuscripts Submitted to a Journal?

An all possible subsets (APS) multiple regression analysis (Onwuegbuzie \& Daniel, 2003; Thompson, 1995) was used to identify an optimal combination of communication vagueness categories (i.e., independent variables) that predicted the number of the APA errors. 
Using this technique, all possible models involving some or all of the independent variables were examined. This method of analysis has been advocated by several researchers (see, for e.g., Onwuegbuzie \& Daniel, 2003; Thompson, 1995). For this study, the criterion used was the maximum proportion of variance explained $\left(R^{2}\right)$, which served as an important measure of effect size (Cohen, 1988).

The APS multiple regression analysis revealed that a model containing communication vagueness categories provided the best fit $(F[4,67]=3.39, p=0.14)$ to the prediction of the number of APA errors, namely, negated intensifiers, indefinite amount, reservations, and anaphora. This variable explained $17.2 \%$ of the variation in the number of APA errors. Using Cohen's (1988) criteria for assessing the predictive power of a set of independent variables in a multiple regression model, the proportion of variance explained indicates a medium effect size, because it lies between $13 \%$ and $25.99 \%$. An inspection of the studentized (i.e., standardized) residuals generated from the model (Myers, 1986) suggested that the assumptions of normality, linearity, and homoscedasticity were met. Using the Bonferroni adjustment, none of the studentized residuals suggested that any outliers were present. The regression model suggests that authors who tended to make the least APA errors were those manuscripts that were higher with respect to reservations and anaphora and lower with regard to negated intensifiers and indefinite amount.

\subsection{Research Question 3. What Is the Relationship Between the Frequency of Communication Vagueness and Citation Errors Among Manuscripts Submitted to a Journal?}

The APS multiple regression analysis revealed that no communication vagueness category predicted the number of citation errors $(F[10,61]=0.68, p=0.74)$. These findings indicate that communication vagueness categories represent a very distinct construct from citation errors. As such, authors who write literature review sections that are characterized by communication vagueness are not necessarily those authors who commit citation errors.

\subsection{Research Question 4. What Is the Relationship Between the Frequency of Communication Vagueness and Select Demographic Characteristics (i.e., Number of Authors, Gender of the Lead Author, Genre of Manuscript) Among Manuscripts Submitted to a Journal?}

The APS multiple regression analysis revealed that no communication vagueness category predicted the number of authors $(F[10,61]=0.79, p=0.63)$. In contrast, an all possible subsets canonical discriminant analysis revealed that a model containing the following five communication vagueness category variables $\left(\times^{2}[5]=11.29, p=.046\right.$; Wilks's Lambda $=$ $0.67)$ predicted the gender of the lead author: ambiguous designation, negated intensifiers, bluffing and recovery, multiplicity, and anaphora. The corresponding canonical correlation was .57, which suggested a large effect size (Cohen, 1988). In addition, the group centroid (the average score on the discriminant function for both gender groups) for this function was .79 for authorship teams with men lead authors and -.58 for authorship teams with women lead authors. These statistics indicated that the discriminant function maximally separated authorship teams with men lead authors from authorship teams with women lead authors. An examination of the standardized canonical discriminant function coefficients (Table 2) revealed that, using a cutoff loading of 0.3 (Lambert \& Durand, 1975; Tabachnick 
\& Fidell, 2007), all five communication vagueness categories were practically significant. In contrast, the structure coefficients (i.e., structure matrix) between the independent variable set and the standardized canonical discriminant function (Table 2) indicated that, using a cutoff loading of 0.3 , the following three variables discriminated authorship teams with men lead authors from authorship teams with women lead authors: negated intensifiers, ambiguous designation, and multiplicity. However, bluffing and recovery and anaphora did not discriminate these two groups of lead authors. Moreover, a comparison of the standardized and structure coefficients (Table 2) revealed that bluffing and recovery and anaphora served as suppressor variables because they had significant standardized coefficients (i.e., > .30) but non-significant structure coefficients (Henson, 2002; Onwuegbuzie \& Daniel, 2003). In Table 2 , communication vagueness categories with a positive coefficient (i.e., negated intensifiers, ambiguous designation, and multiplicity) indicated that authors high on these categories were more likely to represent manuscripts written by authorship teams with women lead authors. Conversely, communication vagueness categories with negative coefficients (i.e., bluffing and recovery and anaphora) indicated that authorship teams high on these categories were more likely to be categorized as authorship teams with men lead authors.

Table 2. Standardized and structure coefficients for selected variables predicting gender of lead author

\begin{tabular}{|l|l|l|}
\hline Variable & Standardized Coefficient & Structure Coefficient \\
\hline ambiguous designation & $1.78^{*}$ & $.50^{*}$ \\
\hline negated intensifiers & $0.98^{*}$ & $.51^{*}$ \\
\hline multiplicity & $0.84^{*}$ & $.35^{*}$ \\
\hline anaphora & $-2.02^{*}$ & .28 \\
\hline bluffing and recovery & $-1.13^{*}$ & .10 \\
\hline
\end{tabular}

Note. ${ }^{*}$ coefficients with effect sizes larger than .3 (Lambert \& Durand, 1975).

Further, an all possible subsets canonical discriminant analysis revealed a statistically significant first canonical function $\left(\times^{2}[10]=18.94, p=.041\right.$; Wilks's Lambda $\left.=0.72\right)$ for a model containing the following five communication vagueness category variables that predicted the genre of the manuscript (i.e., quantitative research manuscripts vs. qualitative research manuscripts vs. mixed methods research manuscripts): negated intensifiers, approximation, multiplicity, probability and possibility, and anaphora. However, the second canonical function $\left(\times^{2}[4]=3.44, p=.041\right.$; Wilks's Lambda $\left.=0.49\right)$ was not statistically significant. Thus, only the first canonical function was interpreted. The corresponding canonical correlation pertaining to the first canonical function was .49 , which suggested a large effect size (Cohen, 1988). In addition, the group centroid for this function was -.48 for quantitative research manuscripts, -.05 for qualitative research manuscripts, and .84 for 
mixed methods research manuscripts. These statistics indicated that the discriminant function maximally separated quantitative research manuscripts and qualitative research manuscripts from mixed methods research manuscripts. An examination of the standardized canonical discriminant function coefficients, for the first canonical function (Table 3), revealed that, using a cutoff loading of 0.3 (Lambert \& Durand, 1975; Tabachnick \& Fidell, 2007), negated intensifiers, approximation, and multiplicity were practically significant, with approximation, by far, making the greatest contribution. Further, the structure coefficients for the first canonical function (Table 3) indicated that, using a cutoff loading of 0.3 (Lambert \& Durand, 1975; Tabachnick \& Fidell, 2007), all five communication vagueness categories were practically significant, with approximation, again, making the greatest contribution. A comparison of the standardized and structure coefficients revealed no suppressor variables nor collinearity because all the variables with significant standardized coefficients (i.e., > .30) also had significant structure coefficients (Henson, 2002; Onwuegbuzie \& Daniel, 2003). However, the fact that probability and possibility and anaphora both had significant structure coefficients but non-significant standardized coefficients suggest that these variables might have been collinear (Onwuegbuzie \& Daniel, 2003). In any case, approximation made the most noteworthy contribution in discriminating quantitative research manuscripts and qualitative research manuscripts from mixed methods research manuscripts. In Table 3, communication vagueness categories with a positive coefficient (i.e., approximation, multiplicity, and probability and possibility) indicated that authors high on these categories were more likely to represent mixed methods research manuscripts. Conversely, communication vagueness categories with negative coefficients (i.e., negated intensifiers and anaphora) indicated that authors high on these categories were less likely to represent mixed methods research manuscripts.

Table 3. Standardized and structure coefficients for selected variables predicting genre of manuscript

\begin{tabular}{|l|l|l|}
\hline Variable & Standardized Coefficient & Structure Coefficient \\
\hline negated intensifiers & $-0.83^{*}$ & $-.40^{*}$ \\
\hline approximation & $0.75^{*}$ & $.63^{*}$ \\
\hline multiplicity & $0.32^{*}$ & $.45^{*}$ \\
\hline probability and possibility & 0.29 & $.33^{*}$ \\
\hline anaphora & -0.12 & $.36^{*}$ \\
\hline
\end{tabular}

Note. ${ }^{*}$ coefficients with effect sizes larger than .3 (Lambert \& Durand, 1975).

\subsection{Research Question 5. What Is the Relationship Between the Frequency of Communication} Vagueness and Manuscript Disposition Among Manuscripts Submitted to a Journal? 
A canonical discriminant analyses was conducted to determine which of the communication vagueness categories best predicted whether the editor's decision for a manuscript was reject versus non-reject (i.e., revise and resubmit or accept). The canonical discriminant analysis revealed that a model containing the following three communication vagueness category variables $\left(\times^{2}[3]=9.14, p=.027\right.$; Wilks's Lambda $\left.=0.87\right)$ predicted the disposition of a manuscript: bluffing and recovery, probability and possibility, and admission of error. The corresponding canonical correlation was .36, which suggested a medium effect size (Cohen, 1988). In addition, the group centroid for this function was .37 for manuscripts that were rejected and -.40 for manuscripts that were not rejected. These statistics indicated that the discriminant function maximally separated manuscripts that were rejected from manuscripts that were not rejected.

An examination of the standardized canonical discriminant function coefficients (Table 4) revealed that, using a cutoff loading of 0.3 (Lambert \& Durand, 1975; Tabachnick \& Fidell, 2007), all three communication vagueness categories (i.e., bluffing and recovery, probability and possibility, and admission of error) were practically significant, with admission of error making the biggest contribution. Further, the structure coefficients (Table 4) indicated that, using a cutoff loading of 0.3 , again, all three communication vagueness categories were practically significant, with bluffing and recovery making the biggest contribution. The communication vagueness categories with a positive coefficient (i.e., bluffing and recovery, probability and possibility) suggests that manuscripts high on this measure were more likely to be rejected. Conversely, the measure with a negative coefficient (i.e., admission of error) indicates that manuscripts low on this measure were less likely to be rejected.

Table 4. Standardized and structure coefficients for selected variables predicting manuscript disposition

\begin{tabular}{|l|l|l|}
\hline Variable & Standardized Coefficient & Structure Coefficient \\
\hline bluffing and recovery & $1.00^{*}$ & $.79^{*}$ \\
\hline probability and possibility & $1.02^{*}$ & $.61^{*}$ \\
\hline admission of error & $-1.32^{*}$ & $.30^{*}$ \\
\hline
\end{tabular}

Note. ${ }^{*}$ coefficients with effect sizes larger than .3 (Lambert \& Durand, 1975).

\section{Discussion}

The present study is unique in at least four ways. First, it represents the only study in which the prevalence of communication vagueness in manuscripts submitted for publication has been examined. Second, it represents the first formal attempt to examine the link between the frequency of communication vagueness and style guide errors-namely, APA errors and citation errors-among manuscripts submitted to a journal. Third, this investigation represents the first study to investigate the relationship between the frequency of 
communication vagueness and select demographic characteristics (i.e., number of authors, gender of the lead author, genre of manuscript) among manuscripts submitted to a journal. Fourth, and most importantly, this study represents the first attempt to examine the relationship between the frequency of communication vagueness and manuscript disposition among manuscripts submitted to a journal.

Overall, the results from this current study demonstrated several unique findings in relation to communication vagueness and manuscript preparation and submission. In particular, the frequency of communication vagueness differs in relation to the following: (a) number of APA errors, (b) gender of lead author, (c) genre of manuscript, and (d) adjudication decisions. Clearly, the most notable finding is that manuscripts that are less likely to draw favorable reviews - and, hence, are more likely to be rejected for publication - are more likely to involve literature review sections wherein the author does not communicate effectively and, more specifically, attempts to shift responsibility for making sense of the content to the reader, using words such as anyway (i.e., bluffing and recovery). Also, these manuscripts that are at risk for rejection are more likely to involve literature review sections that lack clarity or definite knowledge, being categorized by words/phrases such as at times (i.e., probability and possibility). This finding suggests that communication vagueness associated with these categories reduces the coherence of the literature review section and, in turn, the coherence of a manuscript, which, in turn, make it more difficult for readers in general and journal reviewers in particular to follow the author's logic of argumentation. Based on these findings, it appears that when a literature review does not contain certain categories of communication vagueness, it is well received by consumers.

Some researchers (e.g., Jagsi et al., 2006) have documented that, across numerous fields, women are underrepresented as lead authors. This was the rationale behind examining communication vagueness as a function of gender of the lead author. The statistically significant and practical significant relationship between certain communication vagueness categories and gender of the lead author is interesting. That authorship teams with women lead authors were more likely to submit manuscripts that contained higher levels of communication vagueness associated with negated intensifiers, ambiguous designation, and multiplicity and that authorship teams with men lead authors were more likely to submit manuscripts that contained higher levels of communication vagueness associated with bluffing and recovery and anaphora, suggest that communication vagueness might have a gender context. In any case, this potential link is worthy of further investigation.

Also, worthy of additional study is the finding that communication vagueness associated with approximation, multiplicity, and probability and possibility are more likely to represent the literature review sections of mixed methods research manuscripts, whereas communication vagueness associated with negated intensifiers and anaphora are less likely to represent mixed methods research manuscripts. Interestingly, to some degree, this finding is consistent with the link between genre of manuscript and readability documented by Onwuegbuzie, Mallette, Hwang, and Slate (2013). Using the Flesch Reading Ease (RE) and Flesch-Kincaid Grade Level (GL), two common and easily accessible readability formulas, these researchers observed that the text in manuscripts in which authors reported on studies using quantitative 
methods yielded statistically and practically significant lower RE scores and higher GLs than the text in manuscripts in which authors reported on qualitative research studies. Thus, it is likely that communication vagueness, readability, and manuscript genre are linked in some important way. As such, the present study should be replicated and extended to include measures of readability (e.g., Flesch Reading Ease, Flesch-Kincaid Grade Level).

The link found in the present study between communication vagueness and manuscript disposition suggests that more preparation is needed for doctoral students as to how to write the literature review sections of reports (e.g., dissertations, articles). Indeed, as admonished by Boote and Beile (2005), it is imperative that faculty members in institutions of higher learning recognize the central role of the literature review in the preparation of doctoral students as well as "broaden...understanding of what literature reviewing entails" (p. 4). Unfortunately, as noted previously, compared to research methodology courses, the literature review is regarded as being of secondary importance (Boote \& Beile, 2005; Onwuegbuzie \& Frels, 2016). Yet, without such training in literature reviewing, it is likely that many students will continue "to lack the knowledge and skills even to complete thorough summaries of the existing literature, let alone more sophisticated forms of research synthesis" (Boote \& Beile, 2005 , p. 4). And rather than assuming that doctoral students can train themselves in literature reviewing, the skills needed to write sophisticated literature reviews that lack communication vagueness should be taught explicitly.

One way of teaching these skills explicitly is via the implementation of courses on literature reviewing. And these literature review courses should be taught by faculty who are experienced at conducting literature reviews and, preferably team-taught with librarians because this combination of instructors has been found to be effective because neither faculty members nor librarians by themselves typically have the necessary knowledge and skills to teach a literature review course alone (Bruce, 2001; Caspers \& Lenn, 2000). However, implementing a stand-alone literature review course into a doctoral curriculum is not sufficient (Boote \& Belie, 2005). Instead, knowledge and skills of literature reviewing should permeate the doctoral curriculum, optimally being incorporated into as many doctoral courses as possible in such a way that literature review skills are not taught in isolation. Most importantly, as advocated by Isbell and Broaddus (1995), and as indicated by the current findings, in these courses, writing instruction (e.g., the mechanics of writing, rhetoric) should be incorporated into the literature review process. Without such writing skills, how can faculty members expect doctoral students to write sophisticated literature reviews that lack communication vagueness? And without the ability to write sophisticated literature reviews, it will be difficult for students to be effective consumers and producers of research.

\section{References}

Alton-Lee, A. (1998). A troubleshooter's checklist for prospective authors derived from reviewers' critical feedback. Teaching and Teacher Education, 14, 887-890. https://doi.org/ 10.1016/S0742-051X(98)90000-2

Boote, D. N., \& Beile, P. (2005). Scholars before researchers: On the centrality of the dissertation literature review in research preparation. Educational Researcher, 34(6), 3-15. 
https://doi.org/10.3102/0013189X034006003

Boote, D. N., \& Gaudelli, W. (2002). The use and abuse of historical educational theorists: Comments on recent Dewey scholarship. Insights: A publication of the John Dewey Society for the Study of Education and Culture, 35(2), 9-13.

Bruce, C. S. (2001). Faculty-librarian partnerships in Australian higher education: Critical dimensions. Reference Service Review, 29, 106-115. https://doi.org/10.1108/00907320110 394146

Caspers, J., \& Lenn, K. (2000). The future of collaboration between librarians and teaching faculty. In D. Raspa \& D. Ward (Eds.), The collaborative imperative: Librarians and faculty working together in the information universe (pp. 148-154). Chicago, IL: American Library Association.

Cohen, J. (1988). Statistical power analysis for the behavioral sciences (2nd ed.). Hillsdale, NJ: Lawrence Erlbaum.

Combs, J. P., Bustamante, R. M., \& Onwuegbuzie, A. J. (2010). An interactive model for facilitating development of literature reviews. International Journal of Multiple Research Approaches, 4, 159-182. https://doi.org/10.5172/mra.2010.4.2.159

Cooper, H. M. (1985). The literature review: Knowledge synthesis activities in education and psychology. Invited address at the annual meeting of the American Educational Research Association, Chicago, IL.

Henson, R. K. (2002). The logic and interpretation of structure coefficients in multivariate general linear model analyses. Paper presented at the annual meeting of the American Educational Research Association, New Orleans, LA.

Hiller, J. H. (1971). Verbal response indicators of conceptual vagueness. American Educational Research Journal, 8, 151-161. https://doi.org/10.3102/00028312008001151

Hiller, J. H., Fisher, G. A., \& Kaess, W. A. (1969). A computer investigation of verbal characteristics of effective classroom lecturing. American Educational Research Journal, 6, 661-675. https://doi.org/10.3102/00028312006004661

Isbell, D., \& Broaddus, D. (1995). Teaching writing and research as inseparable: A faculty-librarian teaching team. Reference Services Librarian, 48, 5-25. https://doi.org/ 10.1108/eb049264

Jagsi, R., Guancial, E. A., Worobey, C. C., Henault, L. E., Chang, Y., Starr, R., \& Hylek, E. M. (2006). The "gender gap" in authorship of academic medical literature-A 35-year perspective. New England Journal of Medicine, 385, 281-287. https://doi.org/10.1056/ NEJMsa053910

Lambert, Z. V., \& Durand, R. M. (1975). Some precautions in using canonical analysis. Journal of Market Research, 12, 468-475. https://doi.org/10.2307/3151100

LeCompte, M. D., Klingner, J. K., Campbell, S. A., \& Menk, D. W. (2003). Editors' 
introduction. Review of Educational Research, 73, 123-124. https://doi.org/10.3102/003465 43073002123

Mullins, G., \& Kiley, M. (2002). "It's a PhD, not a Nobel Prize”: How experienced examiners assess research theses. Studies in Higher Education, 27, 369-386. https://doi.org/10.1080/ 0307507022000011507

Myers, R. H. (1986). Classical and modern regression with applications. Boston, MA: Duxbury Press.

Onwuegbuzie, A. J., \& Daniel, L. G. (2003). Typology of analytical and interpretational errors in quantitative and qualitative educational research. Current Issues in Education, 6(2). Retrieved from http://cie.asu.edu/ojs/index.php/cieatasu/article/view/1609/0

Onwuegbuzie, A. J., \& Daniel, L. G. (2005). Editorial: Evidence-based guidelines for publishing articles in Research in the Schools and beyond. Research in the Schools, 12(2), 1-11. Retrieved from http://www.msera.org/download/Rits_editorial_12_2.pdf

Onwuegbuzie, A. J., \& Frels, R. K. (2012). Writing a literature review. In C. Wagner, B. Kawulich, \& M. Garner (Eds.), Doing social research: A global context (pp. 29-51). Maidenhead, England: McGraw-Hill.

Onwuegbuzie, A. J., \& Frels, R. K. (2016). Seven steps to a comprehensive literature review: A multimodal and cultural approach. London, England: Sage.

Onwuegbuzie, A. J., \& Leech, N. L. (2005). A typology of errors and myths perpetuated in educational research textbooks. Current Issues in Education, 8(7). Retrieved from http://cie.ed.asu/volume8/number7

Onwuegbuzie, A. J., \& Poth, C. A. (2015). Editors' Afterword: Toward evidence-based guidelines for reviewing mixed methods research manuscripts submitted to journals. International Journal of Qualitative Methods, 14, 122-125. https://doi.org/10.1177/16094069 16628986

Onwuegbuzie, A. J., Collins, K. M. T., Leech, N. L., Dellinger, A. B., \& Jiao, Q. G. (2010). A meta-framework for conducting mixed research syntheses for stress and coping researchers and beyond. In G. S. Gates, W. H. Gmelch, \& M. Wolverton (Series Eds.); K. M. T. Collins, A. J. Onwuegbuzie, \& Q. G. Jiao (Eds.), Toward a broader understanding of stress and coping: Mixed methods approaches (pp. 169-211). The Research on Stress and Coping in Education Series (Vol. 5). Charlotte, NC: Information Age Publishing.

Onwuegbuzie, A. J., Leech, N. L., \& Collins, K. M. T. (2011). Innovative qualitative data collection techniques for conducting literature reviews. In M. Williams \& W. P. Vogt (Eds.), The Sage handbook of innovation in social research methods (pp. 182-204). Thousand Oaks, CA: Sage. https://doi.org/10.4135/9781446268261.n13

Onwuegbuzie, A. J., Mallette, M. H., Hwang, E., \& Slate, J. R. (2013). Editorial: Evidence-based guidelines for avoiding poor readability in manuscripts submitted to journals for review for publication. Research in the Schools, 20(1), i-xi. 
Provalis Research. (2014a). QDA Miner (Version 4.1.33) [Computer Software]. Retrieved from https://provalisresearch.com/order

Provalis Research. (2014b). WordStat (Version 7.1.6) [Computer Software]. Retrieved from https://provalisresearch.com/order

Tabachnick, B. G., \& Fidell, L. S. (2007). Using multivariate statistics (5th ed.). Boston, MA: Allyn \& Bacon. Retrieved from http://www.census.gov/hhes/www/income/data/statemedian

Thompson, B. (1995). Stepwise regression and stepwise discriminant analysis need not apply here: A guidelines editorial. Educational and Psychological Measurement, 55, 525-534. https://doi.org/10.1177/0013164495055004001

Zaporozhetz, L. E. (1987). The dissertation literature review: How faculty advisors prepare their doctoral candidates (Unpublished doctoral dissertation, University of Oregon, Eugene).

\section{Copyright Disclaimer}

Copyright for this article is retained by the author(s), with first publication rights granted to the journal.

This is an open-access article distributed under the terms and conditions of the Creative Commons Attribution license (http://creativecommons.org/licenses/by/3.0/). 